This is a "Post-Print" accepted manuscript, which has been published in International Review for the Sociology of Sport 2018. 53(6), 745-761

Please cite this publication as follows:

Samu Pehkonen and Hanna-Mari Ikonen: Too good to be a sport? Why dog agility struggles in gaining recognition as a sport. International Review for the Sociology of Sport, ePrint version, Published online: 7 Dec 2016, DOI: $10.1177 / 1012690216679834$

You can download the published version at:

http://journals.sagepub.com/doi/pdf/10.1177/1012690216679834 
Too good to be a sport? Why Dog Agility struggles in gaining recognition as a sport

\begin{abstract}
Over the last two decades, the Finnish community of Dog Agility practitioners has worked diligently towards gaining recognition for Agility as a sport. The process reached an important milestone in $\mathbf{2 0 1 6}$ when the National Sports Council listed the Finnish Agility Association as eligible for financial support from the state. As one of the pioneer countries in this regard, Finland is of great interest, as Agility sport continues to become more popular and professionalised worldwide. Using the findings from a qualitative study of media coverage and expert interviews about attempts to gain recognition for Agility as a sport, this article explores the strategies that practitioners and the Finnish Agility Association have utilised in their work. This article shows that recognition comes with the need to find a balance between elite sports, on the one hand, and sport for all on the other. Although Agility may risk losing some of its particular character as a human-animal teamwork dynamic, it has the potential to contribute to the culture of sports more widely.
\end{abstract}

\title{
Keywords
}

Recognition, sports policies, Dog Agility, Finland, media coverage

Sports is not only about competition between athletes but between different sports as well. This is demonstrated in the process of selecting 'athletes of the year.' In Finland, for example, the annual selection process done by sports journalists-typically middle-aged men with fairly traditional views on sports-tends to rank higher those athletes who represent nationally appreciated sports, such as cross-country skiing or the javelin throw. When the general public gets to vote for their choice, the results may be surprising. One such instance took place in 2006 when a Finnish Dog Agility handler, who had won the World Agility Championship, was ranked fifth by the public - this despite the fact that, at that time, Agility was not officially acknowledged as a sport. In printed and social media, sports fans voiced their outrage about the lack of respect for 'the proper sport' when 'a man who takes his dog for a walk' was voted higher than a top twenty ATP tennis player (Helsingin Sanomat, 2007). In the agility community, the reaction was mixed: The result was viewed as an important step towards recognising Agility as a sport but also a reminder of the challenges to be faced in changing public perceptions about Agility. 
The above incident illustrates both the need for recognition (sought by the agility community) and the lack of acceptance (expressed by part of the general public) of Agility as an emerging sport. This article investigates the agility community's arduous path towards recognition as a sport. In contrast to its invention in the late 1970s as an entertaining intermission at the Crufts Dog Show in the United Kingdom, agility has, over the last decade, steadily become a professional and commercial sport worldwide. Practitioners have started to see themselves as athletes and, consequently, called for equal treatment and recognition vis-a-vis athletes in other sports, as Agility competitions are still mainly run by volunteers with little financial support outside the agility community. In the UK, for example, the Kennel Club's previous preapplications have been rejected, as the Sports Council would only recognise the achievements of people, not dogs or human-dog teams (Parsons, 2014). In Finland, the context of this article, the agility community has chosen to distance itself from the administration of the Finnish Kennel Club and to create new organisational structures tailored for close cooperation with established sport organisations. The first important goal was reached in 2016 when the Finnish Agility Association (SAGI), which includes local agility clubs as members, became eligible for state funding via an announcement by the National Sports Council.

Taking theories of social recognition and acceptance as the conceptual point of departure and locating Agility in the chancing sphere of sports, we assess public discourse about Agility in Finland, concentrating especially on developments in the 2010s. We explore the strategies and arguments raised by the agility community to demonstrate the sportiveness and physical requirements of Agility. We reflect on arguments used by state offices-the Finnish Tax Administration and the Ministry of Education and Culture, who are responsible for developing sports policies through the allocation of funding in Finland-who locate Agility within the realm of dog training under the label of exercise for dogs rather than the advancement of handlers' physical education. We also discuss scepticism emanating from within the agility community, as it includes a diverse group of dog owners in terms of sex, age, and level of commitment. This article suggests that the struggle to gain recognition for Agility takes place within and represents a larger discussion about whether the state should assume a role as a provider of sport for all-in which the primary intention is to increase participation in physical exercise as a means to fight against social and health problems-or participate in the global sporting arms race by supporting competitive elite sports (Bailey and Talbot, 2015; Collins, 2010; Heinilä, 1971). The implications of our analysis are considered in a final discussion about whether recognition-seeking strategies frame Agility in a way that may lead the agility community to abandon some of its unique practices if the elite sports view on physical and 
mental education takes over. Regarding this threat, we address literature on other emerging sports, including lifestyle sports, that are in the process of seeking recognition.

\section{Theoretical review}

\section{Agility and sports}

The quest for Agility's recognition takes place in a changing landscape of sports. On the one hand, the academic discussion on what constitutes a legitimate sport illustrates the contentious and context-sensitive character of any effort to define 'sport' (Coakley, 2001; McFee, 2004). Instead of rigid categorisations, scholars have been directing their attention towards the societal hierarchies of sporting bodies in terms of, for example, (dis)ability (Jarvie, 2009) and gender (Hargreaves, 1994; Pfister, 2015). Here, the question is not so much what a 'sport' is but rather what is considered a proper sport by the gatekeepers in the media, sport organisations, and funding bodies. On the other hand, the emergence of 'post-sports'holistic, physical, and cultural styles of life-is challenging traditional sports practices that 'enframe physical bodies as resources to be deployed toward the attainment of competitive, rule-bound and performative sport outcomes' (Atkinson, 2010: 1250). Atkinson connects postsports with decisively anti-commercial and cooperative athletic practices found, for example, in yoga and fell running.

While engagement in both traditional sports (meaning goal oriented and rule governed) and post-sports (meaning physical and emotional) has an important role to play in society in terms of increasing participation in physical education, there are emerging sports that fit into neither sport category and that, while rooted in strong, resistant subcultures and lifestyle, are striving for official recognition. Recent studies on Ultimate Frisbee (Ultimate) offer valuable insight into this debate. Crocket (2015) argues that Ultimate offers an alternative to the win-at-allcost instrumental rationality of traditional sports. His ethnographic study shows how Ultimate players work to make themselves ethical athletic subjects through the Foucauldian 'practices of the self.' Criggs (2009: 1318) shows how aesthetic appreciation is apparent in the game even when the purposive activity (scoring) remains unfulfilled. Finally, Crocket (2016), by using dress code as a lens, offers an analysis of the debate regarding Ultimate players and whether they should strive to maintain their subcultural values and practices or work to become more recognisably mainstream (see also Criggs, 2011; Beal, 2001; Rinehart, 2000; Wheaton and Beal, 2003).

Sporting animals constitute a particular case in the world of sports. A recent anthology by Gillett and Gilbert (2014: 4; see also Gilbert and Gillett, 2012) make a strong contribution by 
bringing together animal studies, 'exploring the ways in which sport implicates human and non-human species,' and sport studies, 'broadening the view of sport and sporting environments to include animals.' Several chapters in the book discuss horses as an integral part of the Olympic Games, both historical and contemporary. While equestrian sports are often portrayed as a textbook example of sporting animals - and indeed offered as a justification for Agility's status as a sport-there are some profound differences between equestrian sports and canine sports.

For example, Lund (2014), inspired by Haraway (2003), provides an overview of dog-handler teams in Agility. Both Haraway and Lund stress the aspects of reciprocal and voluntary communication and cooperation in Agility. Whereas professional jockeys in horse racing may 'have little or no knowledge of the animal which they are to pilot' (Vamplew, 2016: 384), the cooperative nature of Agility gives the team itself, not the handler or the dog, a unique position in the action. Furthermore, while in general there is an ethical code to be followed in sports (including antidoping, respect for the opponent, etc.), animal-related sports are particularly valued with respect to the ways in which animals are treated (Atkinson and Young, 2005). Schuurman (2014: 8) provides an explanation of the rules of proper behaviour towards one's horse in her analysis of social media and equestrian sports. The relevance of emotional work in Agility might be even more important because Agility practitioners typically share their daily lives with the dogs (Ikonen and Pehkonen, 2016). The fact that dogs have more intimate relationship with their human caretakers and that equestrian sports already have an established (although not uncontested) position in the sports community makes Dog Agility an interesting case of an animal-related lifestyle sport.

In addition to the elements of animal sports and post-sports, Agility seeks a legitimate position in relation to sport funding policies. Although the practitioners could continue their lifestyle sport even without state support, if 'sport' is defined in terms of physical education and exercise that produce well-being and public health benefits, then supporting Agility might bring mutual benefits. Agility may well be an asset in increasing interest and participation in sports (Gilchrista and Wheaton, 2011). This opens up the debate on competitive (elite) sports versus sport for all in two antithetical planning- and decision-making models introduced by Heinilä (1971; see also Bailey and Talbot, 2015). Competitive sports at the elite level demand both personal sacrifices and solid financial and organisational support from the state, and, when taken to extremes, these demands lead to a sporting arms race. The sport-for-all approach emphasises grassroots participation in which personal and public health is favoured over competitive goals. Competitive sports are often career oriented, while sport for all 
encourage people of different ages to become engaged in sports, thus resulting in mixed social relations. With its sports policy, Finland has been a strong supporter of sport for all since the 1960s, contrary to many other Western countries, where state funding has been targeted at elite sports. Sports policy in Finland has been organised to serve the purposes of social policy, particularly social integration and health policies. This has created a high rate of mass participation in sports (see Collins, 2011). During the last decades, however, worries have grown about decreasing participation and worsening health rates. The existing funding system has been criticised for being inefficient in terms of both advancing elite sports and promoting grassroots activities. Although the sports-for-all approach has been practised for decades, it was only the new sports act (2015) that gave the principle a legislative position. The sport act promotes possibilities for various groups of people to engage in sports while reducing inequality, suggesting that established sports organisations have to adapt their strategies and practices to a new social climate. For Agility, this poses an opportunity rather than a problem, as we will discuss later on.

\section{Recognition}

The issue of recognition has been extensively debated in social and political theory from the 1960s onward in terms of various struggles over identity and difference. In one of the key texts on the matter, Taylor (1994) asserts that contemporary politics is often about the need, if not the demand, for recognition. In the field of sports, Hargreaves' (1994) analysis of women's participation in sports and struggle for recognition offers a good example. Through recognition, people seek to form and determine their sense of who they are and the values attributed to their actions. Although theories of recognition initially discussed individual and intersubjective recognition, such theories were later extended to a collective level.

An important reconceptualisation debate initiated by Fraser and Honneth (2003) sought to understand the relationship between recognition and redistribution (meaning claims for resources, which are subject to further struggle), as current capitalist societies are reflected in the political interplay between political and economic spheres. The recognition-redistribution debate also captures the current situation, as capital flows through some sports but not others. Thus, there are continuous struggles for recognition of identity (through social acceptance), on the one hand, and financial support (through political acceptance) on the other, also in relation to Agility.

We take as a cue the analytical definition of recognition suggested by lkäheimo (2002: 450), who asserts that the recogniser (A) recognises the recognisee (B) by giving it an attribute (C) 
because of a particular dimension (D) of B. For example, the state (A) may recognise the agility community (B) by permitting it the status of a sport (C) based on the particularity of the human-animal relationship (D). An important feature in this process is that the recognisee judges the recogniser on the basis of whether the recogniser is in fact capable of conferring recognition (Brandom, 2009). While the National Sports Council and Ministry of Education and Culture are respected as sound recogniser authorities by the sports community in Finland, there are other decision-making authorities too. Most notably, in 2015, the Finnish Tax Administration (FTA) made a preliminary ruling-later supported by the Supreme Administrative Courts-which treats agility-related coaching services with a higher tax rate than other sports, thus equating Agility with dog training and not with human sports. This decision has been criticised by the agility community due to the FTA's lack of information, as it was not able to appreciate the particularities of the human-dog relationship.

While it would be simple enough to say that the agility community seeks recognition from the sports community, advocates of elite sport Agility also need to reflect on and acknowledge attitudes from a wider community of agility practitioners who, in fact, do not always necessarily share the same goals. There is uneasiness about embracing 'sport' as a master frame for the activity within the agility community itself. It is here that one of the most frequent criticisms regarding recognition of the group is voiced: Efforts to gain the status of a sport demand that Agility be represented in terms that cannot be fulfilled by all members of the agility community. Put simply, efforts to make Agility look more sports-like (e.g. representing the sport with young, athletic bodies and fast, agile dogs) may push other people (e.g. seniors and the obese) to the fringe of the community. Ironically, the project of gaining recognition for Agility may lead to a situation in which the lack of recognition inevitably affects identity formation. If calls for public and official recognition are refused or even ridiculed by the general public, negative feelings could result that would not have emerged had the status of the sport not been addressed.

\section{Data and methodology}

This study's purpose is to describe the strategies the agility community has deployed in their efforts for Agility to receive recognition as a sport and the problems encountered during this process. A qualitative approach with discourse analytical methods was adopted because we were interested in discourses related to Agility expressed in the media, policy documents, and expert interviews. A similar approach has been used to study discourses around media representations of women's sports (Markula, 2009). Our particular interest was in patterns of language and related practices in society at large that demonstrate how language both enables 
and constrains ideas about who people (e.g. agility practitioners) are and what they do (Taylor, 2001: 7-9). Due to our insider knowledge (cf. Adjepong, 2015) as former agility handlers, we anticipated that the strategies for advocating Agility's status as a sport would mirror its human-animal composition, although previous comprehensive research on the topic was missing. The country-specific case of Finland was chosen because it represents a country with a successful competition history and explicit aims for developing an organisational structure with linkages both to kennel clubs and sports organisations.

First, we collected a sample of newspaper articles $(n=59)$ from the largest Finnish newspaper, Helsingin Sanomat, from 1990 to 2015 and news articles $(n=51)$ from the webpage for the Finnish Broadcasting Company (YLE) from 2009 to 2016 (see Table 1). Both sets of articles were found by searching for the keyword 'agility' and then ignoring search results that included only a passing reference to agility. We also read agility-related discussion forums and blogs accessible on the Internet. Second, in order to converge the public's as well as the agility community's perception of Agility, we conducted expert interviews with members of the agility community by both phone and e-mail. The questions asked were grouped into three sections and derived from our general research question to explore the strategies used to have Agility recognised as a sport:

1. How (if at all) had their understanding of Agility changed over time? With this set of questions we sought to cover arguments and counterarguments for Agility as a sport.

2. What type of practical measures did they know had been taken by the agility community to gain wider acceptance and visibility within the sports community? Here, we addressed the practices and the scope of lobbing.

3. What did they consider to be the major obstacles in this process? With this last set of questions we teased out any signs of scepticism within the agility community.

Those who volunteered to participate $(n=12)$ included members in trusted positions in the SAGI as well as top handlers, commercial coaches, and media representatives. One should notice that many of these people possess multiple roles and have been involved in the Agility sport for more than a decade. We also contacted nineteen current and former representatives of the National Sports Council, a supportive body of the Ministry of Education and Culture responsible for assessing the criteria for financially supporting sports organisations in Finland. Only four members wanted to share their conceptions about Agility as a sport and how they had become familiar with it in order to make relevant decisions. We agreed to report their views in an anonymised form. The respondents are listed in Table 2. 
In line with the critical discourse analytical tradition, we searched the interviews for recurrent patterns of language as well as frames of legitimisation and argumentation (Fairclough, 2003). The answers provided clear categorisation and the existence of two discursive realms of Agility for all, which emphasises lowering barriers for participation even without competitive goals, and elite sport Agility, which relates to portraying Agility as a competitive elite sport. Both of these discursive realms locate Agility within already existing institutional settings, ranging from concrete organisations (e.g. kennel clubs, national and local sports organisations) to broader ideas of national welfare, equality of physical education, fair play rules, and commercialisation. These discursive realms are concretised in the agility community's strategies and decisions made for gaining recognition for Agility as a sport. Three such major strategies emanating from these discursive realms were identified.

\section{Results}

This section outlines the strategies the agility community has utilised during its history in Finland to gain acceptance and receive recognition for Agility dog agility competition from the general sports community and the reasoning behind these sometimes more, sometimes less consensual strategies. The strategies include (1) achieving and maximising media coverage, (2) carrying out political lobbying, and (3) modifying rules and practices towards professionalism.

\section{Breaking into the media}

The media-both traditional print and new forms of social media-are a central factor in the emergence of new sports and public perceptions about them (Stead, 2008). The first Finnish newspaper specialising in Agility was launched in 1994 with the commitment to represent Agility as a sport, explicitly distancing it from the status as a dog sport and uncompetitive play with dogs. The sportiveness of Agility was enhanced through naming (Agility Sport Bulletin), photojournalistic guidelines (pictures of handlers with their dogs in competitive actions, not handlers posing with dogs), the content of editorials, and, importantly, invitations made to people with various backgrounds and opinions to contribute to the discussion about the development of the sport:

Already from the outset, the journal promoted the view that 'the dog is just an instrument in agility.' It was understandable that it aroused indignation then. But not so much anymore. (Media representative, male)

At the same time, agility-related Internet discussion forums, the oldest of which has been active since 1996, offered another platform both to disagree with and spread information 
about Agility's institutional development. Several informants mentioned the value of having their own journals and Internet forums as a 'training field' to test ideas and search for a consensus within the community: 'Had there not been these informal platforms for discussion, it would have been difficult to present anything more than personal opinions and views for the outsiders' (former SAGI representative, male). Incorporating professional photojournalism was considered extremely important for forming an adept picture of Agility when offering short articles and photos to the mainstream media: 'Reporters in newspapers don't necessarily know much about the sport so it really makes a difference that we can provide them the facts and proper images' (media representative, male).

In Finland, Agility has received moderate public media coverage throughout its history (see Table 1). This has mainly been the result of actions on the part of the agility community rather than interest from the media. Organisers of major local and national competitions have used the local media to advertise events and raise general awareness of the sport (former SAGI representative, male). Articles typically offer a general description of the sport and refer to its increasing popularity. Journalists often emphasise the playful character of the activity, and the long-term work needed to achieve peak performance is not often a part of journalists' interests (YLE, 2015a). Many informants, from experienced competitors to current SAGI representatives, acknowledged and referred to the media image of 'little girls playing and jumping around with their dogs.' Some of our informants found this annoying, while others saw the athletic and unserious side of the sport as coexisting:

When I started competing in the highest class and began improving also my own physical performance, I was really annoyed with all the public shows and exhibitions that labelled agility in terms of 'dogs doing tricks.' If you train yourself six times a week and your aim is in the world championships, you wish your sport was presented as a sport. (Coach-competitor, female).

Previously I was strictly against presenting agility through any other than sport imagery. Nowadays I think we can't be too straight-laced about it. The humorous side can exist there as well. But I would like to emphasise the relevance of the handler and the physical exercise in this sport. (Coach-competitor, male)

Some informants yearned for greater emphasis on the public health aspects of the sport-a point raised even in academic literature on dog ownership and well-being (Bauman et al., 2001; Jennings, 1997). Agility, including everyday exercise with dogs and the warming-up and 
cooling-down period involved in every training session, is considered a sportive lifestyle for many, regardless of their age or previous participation in sports:

I don't practice any physical exercise if agility is not counted. I'm in my late forties and I regularly do speed endurance, sprint running and coordination training . . . I wouldn't go walking in any type of weather, if I didn't have five dogs. (Coach-competitor, female)

This is a good example of the background work evident for the Agility athletes but not necessarily for the general public. As another respondent says: 'In the end, the public image is defined by the general public outside the agility community; to have an effect on those opinions would require that we make visible more of the work done behind the competitive performance.' (Media representative, male)

Although success in major national and international competitions occasionally made it to the headlines in even Helsingin Sanomat, results were not published in the sports section.

Following the decision by the National Sports Council, several newspapers recently decided to include Agility in the sports section. Even before this, however, it has sometimes been possible to communicate the high level of sportiveness and physical and mental capacities involved in Agility in the media, and such articles have been praised by those agility practitioners who strongly support its status as a sport. Recently, an article (YLE, 2015b) exhibited a new type of framing in which the handler-his thoughts about the sport and his performance-formed the central focus. It told an appealing story of a man changing his attitude towards Agility from seeing it as little girls playing with their dogs to seeing it as a demanding sport in which one encounters numerous challenges. The article stressed the handlers' high heart rates and rapid reactions, all while keeping an eye on both the dog and the course that they and their dogs must run in seamless cooperation. Despite the fact that $80 \%$ of practitioners are women, men are typically given the voice and face for the sport. This runs somewhat contrary to the argument that 'agility is equal in terms of gender,' but it is in line with the literature suggesting that male sports receive more attention (Hargreaves, 1994; Pfister, 2015).

In sum, there has been a gradual shift from 'all publicity is good publicity' towards a more controlled type of media recognition that emphasises the otherwise invisible strenuous work, both physical and mental, underlying the visible performance of agility.

\section{Political lobbying}

Bettering the general attitude towards dogs in society has been a long-term common goal for dog communities organised around national kennel clubs. Gaining recognition for Agility in 
terms of sports politics and financing has been advanced in Finland by the Finnish Agility Association (SAGI) since its establishment in 2006. Establishing the SAGI as the democratic governing body was a strategic choice in order to meet the Finnish sports policy criteria while maintaining cooperation with the Kennel Club. The main purpose of the SAGI is to enhance and advance the sport of Agility and to improve the physical, mental, and social capacities of handlers. As one of the former SAGI representatives explain:

I see myself as an evangelist of sports ideology. I have tried to educate agility handlers, make them see how athletes in other sports think and act. I've been in various events where the values of sport organizations have been discussed and we [the agility community] can fully agree on those values. (Former SAGI representative, male)

With the SAGI's goals, and the assurance that each goal is fulfilled based on ethical values and fair play as well as gender equality, the SAGI has positioned itself firmly in line with traditional sports associations, which have a great deal of autonomy despite state support. The SAGI has implemented strategies for both elite sports and sport for all. However, its preexisting connection with the Finnish Kennel Club has created problems regarding the SAGI's status among sports associations.

One of the first political tasks the SAGI became involved in was applying for membership in the Finnish Sports Confederation as a continuation of local-level development, through which many Agility clubs had already been granted local memberships. In 2009, the SAGI was appointed an associate member in the Finnish Sports Confederation, thus gaining partial recognition. Efforts to apply for state funding were largely unsuccessful until March of 2016, when the National Sports Council proposed to the Ministry of Culture and Education that Agility should receive state funding. The reasons behind the decision were numerous. First, the new sports act (Act on the Promotion of Sports and Physical Activity 390/2015) provides more room for defining the eligibility criteria. The act as well as the council emphasise sports in terms of the Finnish word liikunta (physical exercise) instead of urheilu (sport). The council members stated that Finnish society needs every avenue to increase people's physical education and leisure time activity: 'Finnish people need to move. [Agility] enhances movement and joins families' (state representative, female). Another member explicitly stated the distinction between exercise and elite sports:

Agility is sport in terms of competition between dogs and the way they are handled. I consider more important the physical exercise that is needed to handle the dog and this is the best argument for financial support from the state ... Elite sport is more and 
more commercial business and important as such but we need to support physical exercise. (State representative, male)

Second, the SAGI utilised this formative moment by reorganising application and budget plans. It also invested time to contact council members and politicians to share information about the benefits of Agility in terms of national health and to correct any possible misunderstandings about the sport. Below is an example of lobbying:

How, if in any way, have you tried to promote Agility as a sport, and whom have you tried to affect? What kind of information have you provided? (An e-mail interview question)

I have visited the Parliament to talk and present agility as a sport. In addition, we delivered a lot of background material for the Members of Parliament to lobby them. (Member of trust, coach, male)

Based on the answers, it is not possible to conclude whether the personal opinions of the members of the council had changed in the meantime or whether it was due to political lobbying or changes in the general sports environment. Both the council and the SAGI seem to agree that hindrances have mostly been related to Agility's connection to the Finnish Kennel Club, which also hosts other dog-related hobbies. There was a fear (explicitly worded by the Tax Administration) that recognising Agility as a sport could lead to advocates of other dogrelated activities making similar claims.

The next phase, according to many respondents, will be to challenge a decision made by the Finnish Tax Administration, with confirmation from the Supreme Administrative Court, that agility-related services (the renting of training facilities, training fees) should be taxed with a higher percentage than other sports-related services-for example, in horseback riding. According to the FTA, renting an agility facility does not qualify as a service relating to physical exercise and sports. Thus, Agility does not count as exercise for human participants and is merely considered dog training. This decision has been met with harsh criticism from the agility community. The main reasons behind the FTA decision seem to be the short duration of the run (up to one minute), the fact that the handler moves beside the dog, not on the dog (as in riding a horse), and the possible misuse of the training facility to engage in other dog sports (Rintala, 2016).

In sum, lobbying in the way of providing first-hand information about the unique characteristics of Agility, including the sport's ethical values and its public health benefits, has 
been targeted at those authorities that the agility community itself judges to be relevant in terms of making the decision about whether Agility is sport or not. Although this strategy has been successful in terms of the National Sports Council's decision to recognise the SAGI in the list of organisations eligible for state support, new obstacles have emerged on the way, the latest being the taxation issue.

\section{Modifying rules and practices towards professionalism}

In Agility, the course-planning guidelines by judges and competitors' practices have changed drastically since the 1970s. While courses during previous decades were technically easy, contemporary courses are challenging in terms of the speed and quick reactions needed. With a dog's average running speed on the course being up to six metres a second, the difference between success and failure is determined by reactions executed within hundredths of seconds. Some obstacles have been altered to guarantee the safety of dogs running at a high speed. Judges have also agreed on guidelines concerning training on the course after disqualification: The competition performance now should not include elements of trainingwhich is a visible step towards Agility being a serious sport-whereas previously the shared objective among practitioners was to help their dogs perform the course and obtain positive feelings. All genders and all ages still compete in the same classes-only the success of the dog handler's team matters.

Informants with a competition background also emphasised the changes in their own practices. Although they previously just attended the competitions, they now carefully plan their year with separate training and competition periods while keeping in mind their dogs' well-being and competitive edge. This is, however, challenging due to the simultaneous existence of the elite-sport and sports-for-all discourses. Actually, how the all-inclusivenes of Agility is applied in competition practice has been criticised as something that does not happen in serious sports:

I think it's wrong and unfair that those people who take this only as a hobby without any competitive goals have to compete in the same class with those who set high goals for themselves and want to succeed. In no other sport are these same people competing head to head. It's just depressing for those who never win. And although they say they don't mind but yet they do [laughs]. (Coach-competitor, female).

Also, the competition day has been reorganised. Previously, competitions might have taken a whole day with a loose timetable (as they still do in many countries), but many current competitions (especially championships) follow a tight schedule, with efforts made to make 
the final runs a peak experience for spectators as well as participants. One future direction suggested by some informants would be to set up a ranking system or a separate champion class in which only the elite teams would compete against each other. This would make marketing and branding of the sport easier while still involving the masses.

Dividing Agility into an elite sport and a sport for all is not only manifested in the proposed development of competition classes and rules but also through the commercialisation of Agility as a sport with the goal of opening up more possibilities for private sponsorships and professionalising the most successful practitioners. Although commercial firms cannot organise official competitions in Finland, commercial coaches point out the potential for cooperation in, for instance, developing training programmes. In today's Agility, dogs must be trained in a more thoughtful and ethical manner, and mental coaching of handlers has become common in order to help them tackle competitive situations. Commercial coaches sell these services, for which they have obtained knowledge from sports with a longer coaching history. As one coach says, 'agility coaches are communicating with coaches from more established sports and modifying those practices to fit our needs' (coach-competitor, male).

In addition, the personal branding of the most successful handlers is an increasing trend, as the most successful coach-competitors offer coaching services worldwide (Ikonen and Pehkonen, 2016). This opens up space for introducing physical enhancement practices also for those foreign practitioners 'who previously didn't warm up their dogs or anything, but now ... are doing that, at least those who follow our [commercial] training system, they become aware of taking care of the physical performance' (coach-competitor, female). Ethical role models possess the ability to lead the way towards a professional sports culture in which, as a special characteristic of dog sports, attention is also paid to the well-being, warming up, and care of dogs. Here, an explicit comparison is made between Agility and equestrian sports:

Sport horses' wellbeing is easy to understand by laypeople because horses are known to be 'expensive,' so horse owners should take good care of them. Many issues around dogs raise negative thoughts, street dogs and biting cases, for example. Because of the popularity and large number of dogs, laypeople may not even be aware of all the responsibilities related to sport dogs' wellbeing. (Media representative, male)

In sum, the informants composed the subcultural speciality of Agility as having to do with that it is practiced with a companion animal whose well-being is carefully taken care of alongside the sportive and ethical performance of the handler. Maintaining the plausibility of this practice should not be endangered by efforts to fit the outside norms of sports culture. 


\section{Discussion: Good enough-but for how long?}

Our analysis of the Finnish agility community's strategies to receive recognition for Agility was sparked by the question of why Agility has struggled to gain public recognition as a sport. While some issues in the process of legitimising Agility's position in the field of sports and sports funding are country specific (e.g. how the agility community organises itself and what type of organisational sporting and funding landscape they seek to attract), the questions pertaining to the nature of the sport are universal. However, while the agility community may develop explicit strategies for recognition, the process includes wider discourses, which not all community members are aware of. Moreover, recognising Agility's special attributes sport-like, such as the close relationship between the human and the dog (cf. Ikäheimo, 2002), Agility seems to raise questions that other sports do not. Agility is a team sport in a distinct and unique way. It joins the only two sports in the Olympic Games-the equestrian sports and the $49 \mathrm{er}$ class in sailing - in which men and women compete against each other. In addition, a typical competition includes men and women of all ages. It also offers physical and mental challenges for handlers regardless of their previous involvement in sports. At the same time, however, inside the agility community, some participants would like to establish separate classes or competitions for top dog-handler teams only. Ranking-based classes would maintain competitive edge and help create athletic identity while at the same time lowering the barriers for participating in competitions for those practitioners without professional ambitions and goals. Similar questions have been raised in Ultimate Frisbee (Crocket, 2016), which in its similarity provides another opportunity to continue thinking about the constitution of ethical sports.

Agility is based on a distinct ethical relationship between handlers and their dogs, and success is impossible without mutual commitment (Haraway, 2003; Lund, 2014). While Agility has many similarities with equestrian sports, the relationship between the handler and the dog is strongly built by shared daily life, in which mutual recognition, love, and affection are present (Ikonen and Pehkonen, 2016). Recognising Agility as a sport also presupposes improving the role of dogs in society and the inclusion of dogs in the community of athletes. Resistance continues, perhaps, because in this case the athlete's companion is 'only' a dog, not an expensive and historically valuable horse. Perhaps it is the all-encompassing nature of Agility that has made it appear even too good among the traditional human sports. There is recent interest in the inclusion of lifestyle sports, such as kiteboarding and skateboarding, in the family of Olympic sports. Unlike in Agility, these lifestyle sports are often male dominated and targeted for a younger generation, and they are not necessarily capable of increasing people's 
physical activity throughout their lifespan. The new sports act, with its strong emphasis on sport for all and public health, has provided a clear benefit for the recognition of Agility in Finland.

What is needed globally is a culture that views dogs as sportive companions. Although we do not wish to downplay the unique value of subcultural characteristics and the potential for resisting hegemonic sports values, we claim that Agility seems to evoke values already considered positive in the sports world. Although some studies (Cutt et al., 2007; McNicholas et al., 2005) have questioned the earlier optimistic research (e.g. Headey, 1999) on the positive benefits of dog ownership for the well-being of citizens, the social bond of companionship with sporting animals is something that makes political and financial support for Agility no worse than other sports that have their own pros and cons for society.

There are fears within the agility community that some of the good virtues put forward in Agility will fade with its establishment as a sport. The rules of all-inclusive fair play, for example, may be put under pressure if the sport is intensively pushed towards the direction of elite competition. The aim to win by whatever means as well as to gain the most possible media attention and recognition as an audience-friendly elite sport may be a risk. At the moment, the Agility sport has a strong positive basis in terms of the inclusion of people of different genders, ages, physical capacities, and other characteristics (although different ethnic backgrounds are not well-represented in Finland). It also offers social networks across social classes and other social groups. In addition, the inherent role of dogs in the sport means that their human partners have learnt to take into account team members and other actors, too. There is a high level of both intellectual beauty and ethical athletic subjectivity in Agility, as Criggs (2009) and Crocket (2015) write about Ultimate, because athletes are not always looking for clean runs but also smooth lines and harmonious flow between human and animal team members in the performance. These factors may offer noteworthy principles for other sports and their media image in a path towards 'physical cultures which explore opportunities for participants to relate to themselves and others in a more caring manner than instrumentally rational athletes who seek to dominate their opponent and treat their own bodies as expendable tools in pursuit of victory' (Crocket, 2015: 90).

\section{References}


Adjepong A (2015) 'We're, like, a cute rugby team': How whiteness and heterosexuality shape women's sense of belonging in rugby. International Review for the Sociology of Sport.

Published online before print 28 April, 2015, doi: 10.1177/1012690215584092

Atkinson M (2010) Entering scapeland: yoga, fell and post-sport physical cultures. Sport in Society 13(7-8): 1249-1267.

Atkinson M and Young K (2005) Reservoir Dogs: Greyhound Racing, Mimesis and SportsRelated Violence. International Review for the Sociology of Sport 40(4): 335-356.

Bailey R and Talbot M (eds) (2015) Elite Sport and Sport-for-All: Bridging the Two Cultures. London and New York: Routledge.

Bauman AE, Russell SJ, Furber SE and Dobson AJ (2001) The epidemiology of dog walking: An unmet need for human and canine health. The Medical Journal of Australia 175(11-12): 632634.

Beal B (2001) Disqualifying the official. An exploration of social resistance through the subculture of skateboarding. In: Yiannakis A and Melnick MJ (eds) Contemporary Issues in Sociology of Sport. Champaign: Human Kinetics, pp. 47-57.

Brandom R (2009) Reason in Philosophy: Animating Ideas. Cambridge, MA: Harvard University Press.

Coakley J (2001) Sport in Society: issues and controversies. New York: McGraw Hill.

Collins M (2010) From 'sport for good' to 'sport for sport's sake' - not a good move for sports development in England? International Journal of Sport Policy and Politics 2(3): 367-379.

Collins S (2011) Finland. In: Nicholson M, Hoye R and Houlihan B (eds) Participation in Sport. International Policy Perspectives. London and New York: Routledge, pp. 109-125.

Crocket H (2015) Foucault, Flying Discs and Calling Fouls: Ascetic Practices of the Self in Ultimate Frisbee. Sociology of Sport Journal 32(1): 89-105.

Crocket $\mathrm{H}$ (2016) Tie-dye shirts and compression leggings: an examination of cultural tensions within Ultimate Frisbee via dress. Annals of Leisure Research 19(1): 192-211.

Cutt H, Giles-Corti B, Knuiman M and Burke V (2007) Dog ownership, health and physical activity: A critical review of the literature. Health \& Place 13(1): 261-272. 
Fairclough N (2003) Analysing Discourse: Textual Analysis for Social Research. London: Routledge.

Fraser N and Honneth A (2003) Recognition or Redistribution? A Political-Philosophical Exchange. London, New York: Verso.

Gilbert M and Gillett J (2012) Equine athletes and interspecies sport. International Review for the Sociology of Sport 47(5): 632-643.

Gilchrista P and Wheaton B (2011) Lifestyle sport, public policy and youth engagement: Examining the emergence of parkour. International Journal of Sport Policy and Politics 3(1): 109-131.

Gillett J and Gilbert M (eds) (2014). Sport, Animals, and Society. New York: Routledge.

Griggs $G$ (2009) 'When a ball dreams, it dreams it's a Frisbee': the emergence of aesthetic appreciation within Ultimate Frisbee. Sport in Society 12(10): 1317-1326.

Griggs G (2011) 'This must be the only sport in the world where most of the players don't know the rules': operationalizing self-refereeing and the spirit of the game in UK Ultimate Frisbee. Sport in Society 14(1): 97-110.

Haraway D (2003) The Companion Species Manifesto: Dogs, People, and Significant Otherness. Chicago: Prickly Paradigm Press.

Hargreaves J (1994) Sporting Females: Critical Issues in the History and Sociology of Women's Sport. London and New York: Routledge.

Headey B (1999) Health benefits and health cost savings due to pets: Preliminary estimates from an Australian national survey. Social Indicators Research 47(2): 233-243.

Heinilä K (1971) Social meanings of sport for all. In: Oja P and Telama R (eds) Sport for All. Amsterdam: Elsevier Science Publishers, pp. 439-445.

Helsingin Sanomat (2007) Agility löi Niemisen ja Poutiaisen. Sport news in Helsingin Sanomat 7 January, 2007.

Ikäheimo H (2002) On the genus and species of recognition. Inquiry 45: 447-462. 
Ikonen H-M and Pehkonen S (2016) 'I <3 my high-performance dog': Love for the sport in agility coach representations in social media. Manuscript submitted to Sport in Society.

Jarvie G (2009) Identity, recognition or redistribution through sport? In: Harris J and Parker A (eds) Sport and Social Identities. Basingstoke: Palgrave Macmillan, pp. 15-28.

Jennings LB (1997) Potential benefits of pet ownership in health promotion. Journal of Holistic Nursing 15(4): 358-372.

Lund G (2014) Taking teamwork seriously: The sport of dog agility as an ethical model of crossspecies companionship. In: Gillett J and Gilbert M (eds) Sport, Animals, and Society. London: Routledge, pp. 127-139.

Markula P (ed) (2009) Olympic Women and the Media: International Perspectives. Basingstoke: Palgrave Macmillan.

McFee G (2004) Sport, Rules and Values: Philosophical Investigations into the Nature of Sport. London: Routledge.

McNicholas J, Gilbey A, Rennie A, Ahmedzai S, Dono J-A and Ormerod E (2005) Pet ownership and human health: A brief review of evidence and issues. BMJ 331: 1252.

Parsons S (2014) The 'sport' of agility. Dog World, 17 December, 2014. Available at: http://www.dogworld.co.uk/product.php/127988/1/the_\%E2\%80\%98sport\%E2\%80\%99_of_a gility_by_simon_parsons (accessed 25 March 2016).

Pfister G (2015) Assessing the sociology of sport: On women and football. International Review for the Sociology of Sport 50(4-5): 563-569.

Rinehart RE (2000) Emerging Arriving sport: Alternatives to formal sport. In: Coakley JJ and Dunning E (eds) Handbook of Sport Studies. London: Sage, pp. 504-520.

Rintala H (2016) Koiran selkä ei kestä päällä istumista. Verona blog. Available at: https://veroblogit.com/ (accessed 19 April 2016)

Schuurman N (2014) Blogging situated emotions in human-horse relationships. Emotion, Space and Society 13(4): 1-8.

Stead D (2008) Sport and the media. In: Houlihan B (ed) Sport and Society: A Student Introduction. London: Sage, pp. 184-200. 
Taylor C (1994) The politics of recognition. In: Gutmann A (ed) Multiculturalism: Examining the Politics of Recognition. Princeton: Princeton University Press, pp. 25-73.

Taylor S (2001) Locating and conducting discourse analytic research. In: Wetherell M and Taylor S (eds) Discourse as Data: A Guide for Analysis. Milton Keynes: The Open University, pp. $5-48$.

Vamplew W (2016) Still crazy after all those years: continuity in a changing labour market for professional jockeys. Sport in Society 19(3): 378-399.

Wheaton B and Beal B (2003) 'Keeping It real'. Subcultural media and the discourses of authenticity in alternative sport. International Review for the Sociology of Sport 38(2): 155176.

YLE (2015a) Aloittelija testasi agilityn - koiran sijasta ensin mokasi ihminen. YLE Uutiset 20 July, 2015.

YLE (2015b) Onko agilityllä viimein toivoa päästä urheilulajiksi? Shakki ja tikanheitto ovat jo. YLE Uutiset 18 December, 2015. 
Table 1. Agility-related news published by the Finnish Broadcasting Company (YLE 2009-2016) and the largest Finnish daily newspaper, Helsingin Sanomat (1990-2015).

\begin{tabular}{lcc}
\hline Category & YLE $(\boldsymbol{N}=\mathbf{5 1})$ & HELSINGIN SANOMAT (N = \\
& & $\mathbf{5 9 )}$ \\
\hline Event promotions & $8(15 \%)$ & $14(24 \%)$ \\
\hline Practitioner profile & $5(10 \%)$ & $5(8 \%)$ \\
\hline Results & $3(6 \%)$ & $20(34 \%)$ \\
\hline General presentation & $6(12 \%)$ & $3(5 \%)$ \\
\hline Societal issues & $3(6 \%)$ & $7(12 \%)$ \\
\hline Training facilities & $19(37 \%)$ & $3(5 \%)$ \\
\hline Agility as a sport & $1(2 \%)$ & $6(10 \%)$ \\
\hline $\begin{array}{l}\text { Dog agility as a reference } \\
\text { for other animal-related } \\
\text { activities }\end{array}$ & $6(12 \%)$ & \\
\hline
\end{tabular}


Table 2. Respondents.

\begin{tabular}{llll}
\hline Respondent & Status & Gender & Years in Agility \\
\hline $\mathbf{1}$ & Member of trust & Woman & 5 \\
\hline $\mathbf{2}$ & Member of trust & Man & 15 \\
\hline $\mathbf{3}$ & $\begin{array}{l}\text { Member of trust, } \\
\text { coach }\end{array}$ & Woman & 15 \\
\hline $\mathbf{5}$ & $\begin{array}{l}\text { Member of trust, } \\
\text { coach }\end{array}$ & Man & 15 \\
\hline $\mathbf{6}$ & $\begin{array}{l}\text { Member of trust, } \\
\text { coach }\end{array}$ & Man & 10 \\
\hline $\mathbf{7}$ & Coach & Woman & 10 \\
\hline $\mathbf{8}$ & Coach & Woman & 15 \\
\hline $\mathbf{9}$ & Coach, competitor & Man & 15 \\
\hline $\mathbf{1 0}$ & Competitor, coach & Woman & 5 \\
\hline $\mathbf{1 1}$ & Coach, member of & Man & 10 \\
\hline $\mathbf{1 2}$ & trust & & 10 \\
\hline $\mathbf{1 3}$ & Media representative & Man & 15 \\
\hline $\mathbf{1 4}$ & Media representative & Man & - \\
\hline $\mathbf{1 5}$ & State representative & Man & - \\
\hline $\mathbf{1 6}$ & State representative & Woman & - \\
\hline & State representative & Man & - \\
\hline & State representative & Woman & \\
\hline & & & 10 \\
\hline
\end{tabular}

